Universidade Tecnológica Federal do Paraná - UTFPR

Campus Ponta Grossa - Paraná - Brasil

ISSN: 1981-3686/ v. 9, n. 1: p. 1724-1743, 2015

D.O.I.: http://dx.doi.org/10.3895/rbta.v9n1.2403
Revista Brasileira de Tecnologia

Agroindustrial

\title{
PROPRIEDADES DA POLIGALACTURONASE E PECTINAMETILESTERASE EM PÊSSEGOS [Prunus persica (L.) Batsch] DE CULTIVARES BRASILEIRAS
}

\author{
PROPERTIES OF POLYGALACTURONASE AND \\ PECTINMETHYLESTERASE FROM BRAZILIAN CLINGSTONE \\ PEACHES [Prunus persica (L.) Batsch]
}

\author{
Ricardo Lemos Sainz'; João Luiz da Silva Vendruscolo ${ }^{2}$ \\ ${ }^{1}$ Instituto Federal de Educação, Ciência e Tecnologia Sul-rio-grandense - IFSul - Pelotas - RS - Brasil \\ ricardosainz@pelotas.ifsul.edu.br \\ ${ }^{2}$ EMBRAPA - Centro Nacional de Pesquisa Agropecuária de Clima Temperado - Pelotas - Brasil
}

\begin{abstract}
RESUMO
O presente trabalho objetivou estudar as propriedades das enzimas pécticas em cultivares brasileiras de pêssegos. As enzimas pécticas influem na qualidade dos frutos, especialmente de frutos climatéricos como o pêssego, pois atuam diretamente no amolecimento dos frutos durante sua deterioração, reduzindo sua vida útil. Também têm importância no processamento dos frutos, pois estão diretamente relacionadas com a viscosidade do produto em operações como a clarificação e a concentração. Neste trabalho estudou-se o comportamento e atividade in vitro das enzimas pectinametilesterase (PME) e poligalacturonase (PG) em pêssegos das cultivares Granada, Esmeralda, Jade, Diamante, Granito, Maciel, Eldorado e Jubileu, definindo a enzima mais termoestável da cultivar de menor atividade de PG e PME. A Atividade da PG foi determinada utilizando a metodologia descrita por PRESSEY (1986) e a atividade da PME segundo JEN e ROBISON (1984). As propriedades físicas e químicas foram determinadas segundo AOAC (2000), enquanto a estabilidade térmica das enzimas seguiu o procedimento descrito por LÖWRY (1955). A PG da cv. Eldorado mostrou máxima atividade no entorno do pH 5,0 enquanto que, para a PME, a máxima atividade foi observada no $\mathrm{pH}$ 7,0. Para PG e PME a temperatura ótima foi a de $25^{\circ} \mathrm{C}$. A estabilidade térmica da $P M E$ foi significativamente maior que a da $P G$, decorrente de uma menor constante de velocidade de inativação e maior tempo de meia-vida para qualquer condição de temperatura, podendo ser utilizada como indicador de termoinativação para controle durante o processamento tecnológico de sucos e polpas de pêssegos.
\end{abstract}

Palavras-chave: Pêssegos; PME; PG; Estabilidade térmica.

\section{INTRODUÇÃO}

O mercado de sucos e néctares no Brasil e no mundo encontra-se em pleno crescimento, somente em 2010, foram consumidos 550 milhões de litros de sucos de todos os sabores no Brasil. Desse total, o consumidor levou para casa 152 milhões de litros (27\%) de suco de sabor uva, incluindo néctares (com até 50\% da fruta) e produtos 100\% natural. Até 1999, o Brasil viveu a "Era do suco de laranja", mas com um volume de venda baixo, de aproximadamente 100 milhões de litros, já no início dos anos 2000 o incremento no consumo de sucos no Brasil, começou a crescer, 
chegando a um crescimento médio de $20 \%$ ao ano. Iniciando-se a "Era do sabor", com outras frutas dominando o mercado. Em 2005, foi maracujá, depois passou para o pêssego e agora é a uva. No ano passado, depois do suco de uva - novo líder de mercado - o sabor mais consumido foi pêssego. O suco de laranja ficou em $3^{\circ}$ lugar. (Fonte: Ibravin - $1^{\circ}$ Seminário do Suco de Uva). O consumo per capita de suco no Brasil é de 2,9 litros por pessoa. Outros países consumem muito mais, mas os sabores preferenciais são laranja e maçã, no caso brasileiro temos o suco de uva com consumo de 0,9 litro per capita. E, embora a região Sul do RS tenha uma produção significativa de pêssegos (Prunus persica L. Batsch), com cerca de 55 mil toneladas na última safra, praticamente toda matéria-prima para produção de sucos é importada dos países do prata .

Porém há poucos estudos relacionados com a atividade e comportamento das enzimas pécticas e pectinolíticas em cultivares de pêssegos brasileriras que são fundamentais no processamento industrial deste fruto (FACHINELLO et al., 1996; MEDEIROS e RASEIRA, 1998; PRESSEY e AVANTS, 1973; PRESSEY, 1986; ANTHON, 2002; FOLHA DE SÃO PAULO, 2000; JORNAL DO COMÉRCIO, 2001; RIGON, 2005). Essas enzimas atuam diretamente sobre o amolecimento dos frutos durante sua deterioração, reduzindo sua vida útil e, ainda, têm importância sobre o processamento tecnológico dos frutos, pois estão diretamente relacionadas com a viscosidade do produto, influindo em operações como a clarificação e a concentração. O efeito residual de enzimas como as pectinametilesterases (PME) e poligalacturonases (PG) também podem interferir sobre a turbidez e coloração de sucos clarificados ao catalisar reações de escurecimento não enzimático, via Reação de Maillard, comprometendo sobremaneira os aspectos sensoriais do produto final e sua vida-de-prateleira (LUH, 1980; ANTHON, 2002; LIMA, 2002 a, b).

As substâncias pécticas constituem a classe de polissacarídeos da parede celular que sofre a mais marcante modificação durante o amadurecimento de frutos. Mudanças em pectinas, associadas ao amadurecimento, têm sido extensivamente documentadas; a solubilização e despolimerização das substâncias pécticas, normalmente acompanham o amaciamento dos frutos durante o amadurecimento. Com o amadurecimento, os poliuronídeos da parede celular aumentam a sua solubilidade em água em resposta a sua despolimerização o que culmina com o amaciamento dos frutos (JEN e ROBINSON, 1984; VILAS BOAS et al., 2000).

As pectinametilesterases - PME (E.C.3.1.1.11) constituem um grupo de enzimas de grande importância à tecnologia de processamento de frutas e hortaliças, pois catalisam a desesterificação substâncias pécticas, hidrolizando grupos metil-éster, produzindo pectinas de menor grau de metilação que servirão de substrato às Poligalacturonases - PG (E.C. 3.2.1.15). No caso específico 
de pêssegos, essas enzimas são extremamente relevantes, pois estão envolvidas no processo de maturação dos frutos e aparecem durante todo o ciclo de desenvolvimento destes (GROSS, 1982; PRESSEY e AVANTS, 1975; ANTHON, 2002; LIMA, 2002 a, b; DRAETTA et al., 1979). A ação das PME é de extrema importância, pois as mudanças texturais, sejam decorrentes do amadurecimento normal ou de danos diversos, estão intimamente ligadas às degradações das pectinas. Ao catalisar a hidrólise dos grupos metílicos das pectinas, formam o substrato das PGs, permitindo a ação destas enzimas, com forte influência sobre a textura dos frutos e, conseqüentemente, conservação ou o processamento dos frutos (LIMA, 2002 b; PAYNTER e JEN, 1974; GONÇALVES, 1998).

As pectinas são secretadas na parede celular sob a forma metil-esterificada, então, desesterificadas pela pectinametilesterase (PME), tornando-se disponíveis para ligações cruzadas intermoleculares com o íon $\mathrm{Ca}^{2+}$. A PG é mais ativa na degradação de pectinas desmetiladas que metiladas. Portanto, a PME, enzima que catalisa a desmetilação do grupo carboxílico C6 de resíduos galacturanosil, pode desempenhar um papel importante na determinação da extensão à qual a pectina é acessível à degradação por PG, estando envolvida no processo de amaciamento (VILAS BOAS et al., 2000).

A preparação de suco clarificado quase sempre envolve tratamentos com enzimas pectinolíticas antes da filtração. A relação entre pectina solúvel e insolúvel depende da cultivar, e esta relação pode variar de safra a safra, sendo influenciada pela atividade das enzimas naturalmente presentes nos frutos. O conhecimento do produto a clarificar é fundamental, pois a aplicação de determinada enzima pode ser desnecessária, devido a sua presença em quantidade suficiente na fruta (YAMASAKI, 1964; LUH, 1980; WOODROOF e LUH, 1975).

Fatores como a temperatura, $\mathrm{pH}$ do suco e a concentração do pool de enzimas, são determinantes para a formação dos flóculos que facilitam a clarificação. As enzimas comerciais atuam numa faixa de $\mathrm{pH}=2,5$ a 6,0 com temperatura variando de $15-55^{\circ} \mathrm{C}$ e dosagem que varia de acordo com o tipo de enzimas e substratos; já as enzimas naturais dos frutos apresentam pH ótimo mais perto da neutralidade e uma faixa um pouco mais restrita de temperatura. Já atividades mais altas de enzimas, como a PME e PG, sobre os frutos podem comprometer a qualidade do fruto para obtenção de sucos clarificados (YAMASAKI, 1964; LUH, 1980; FENNEMMA, 1993).

Durante o processamento dos sucos clarificados as condições a que o pool de enzimas clarificantes é submetido devem ser uniformes e que as enzimas naturais das frutas sejam aproveitadas. Portanto, é interessante conhecer o comportamento e estabilidade térmica da PME e da PG nos frutos de pêssegos (LUH, 1980; FREITAS et al., 1998; GONZALES et al., 1992). 
Neste trabalho estudaram-se as propriedades das enzimas PME e PG em pêssegos de cultivares brasileiras, objetivando-se:

1) Determinar as atividades da PME e PG in vitro, em pêssegos das cultivares Granada, Jade, Esmeralda, Diamante, Granito, Maciel e Jubileu, comparando-as com a cultivar Eldorado;

2) Estudar os efeitos do $\mathrm{pH}$ e temperatura na atividade da PG e PME;

3) Estudar os efeitos da concentração do $\mathrm{NaCl}$ e do substratos pectina sobre a atividade da PME;

4) Definir, entre as duas, a enzima mais termoestável da(s) cultivar(es) que apresentar(em) menor (es) valor(es) de atividade enzimática, determinando a constante de velocidade de inativação $(\mathrm{k})$, energia de ativação (Ea) e tempo de meia-vida $\left(\mathrm{t}_{1 / 2}\right)$.

\section{MATERIAIS E MÉTODOS}

\subsection{Matéria-prima}

Foram selecionados pêssegos de duas safras diferentes, com intervalo de 01 ano entre as amostragens, das cultivares Granada, Jade, Esmeralda, Diamante, Granito, Maciel, Eldorado e Jubileu, totalmente maduros, oriundos do Pomar da Fazenda do Sol Agropecuária S/A, Arroio Grande - RS.

O ponto de maturação foi estabelecido utilizando-se como padrão indicativo à coloração da epiderme. Os frutos foram colhidos 24 horas após o ponto de maturação completa, indicado visualmente pela ausência de coloração verde em toda a epiderme dos frutos, garantindo assim que os frutos estivessem totalmente maduros.

Os frutos foram processados, na Indústria Piloto do Centro de Treinamento e Transferência de Tecnologia em Fruticultura de Clima Temperado e Agroindústria - Campus Pelotas-Visconde da Graça - IFSul, obtendo-se metades, separadas em duas parcelas: uma imediatamente analisada e outra congelada em sacos plásticos de $20 \mathrm{~kg}$, armazenada a $-20^{\circ} \mathrm{C}$, em câmara de congelamento até a realização das análises.

\subsection{Métodos}

As análises foram efetuadas no Laboratório de Tecnologia de Alimentos da EmbrapaCentro Nacional de Pesquisa Agropecuária de Clima Temperado, BR 392 - Cascata - Pelotas - RS. Utilizaram-se valores médios de 2 determinações com 3 repetições cada, totalizando seis resultados para cada variável analisada. 


\subsubsection{Análises Físicas e químicas}

As análises físicas e químicas a que foram submetidos os frutos são $\mathrm{pH}$, acidez titulável (AT), teor de sólidos solúveis totais (SST ou ${ }^{\circ}$ Brix), relação SST/AT, teor de fenóis e teor de ácido ascórbico. Os resultados de $\mathrm{pH}$, acidez titulável, SST, teor de ácido ascórbico foram obtidos de acordo com a metodologia descrita pela AOAC (2000). Os fenóis totais foram determinados pelo método descrito por SINGLETON e ROSSI (1965) e o SST/AT foi obtido pela divisão direta dos valores obtidos de SST e acidez titulável, por amostra.

\subsubsection{Preparo dos extratos enzimáticos}

O extrato enzimático para a poligalacturonase foi obtido conforme adaptação da metodologia descrita por PRESSEY (1986): $100 \mathrm{~g}$ de amostra (pêssegos descaroçados e pelados quimicamente com o uso de hidróxido de sódio - 5 N) foram homogeneizadas com $100 \mathrm{~mL}$ de água (pH ajustado a 3,0 - indicado como ideal no procedimento de extração). Agitou-se em "shaker", por 30 minutos, submetendo-se a mistura a centrifugação de 8000 x g por 20 minutos à $2^{\circ}$. C (Centrífuga Avanti j-25 - Beckman Instruments - USA). A fração insolúvel foi lavada duas vezes com $30 \mathrm{~mL}$ de água por grama de precipitado, sendo novamente centrifugado, nas condições descritas acima. A enzima foi extraída utilizando-se 4,5 g de solução 0,2 molar de cloreto de sódio, tamponado em $\mathrm{pH} 5,5$, para 4,5 g da fração insolúvel, mantida em repouso por 24 horas sob refrigeração à $2^{\circ} \mathrm{e}$, posteriormente, centrifugada a 8000 x g por 20 minutos. A fração insolúvel foi lavada com $\mathrm{NaCl}$ 0,2 $\mathrm{M}$ e o filtrado adicionado ao sobrenadante, constituindo o extrato enzimático, imediatamente utilizado para as determinações.

O extrato enzimático da PME foi obtido conforme metodologia descrita por JEN e ROBINSON (1984) adaptada por LIMA (2002 a). Homogeneizando-se 50,0 gramas da amostra com $50 \mathrm{~mL}$ de água e centrifugando-se a 15000 x g, por 15 minutos. A fração insolúvel da centrifugação foi lavada duas vezes com água, sendo ressuspendido com 50,0 mL de solução 1 molar de cloreto de sódio. Após ajustar o pH para 6,0 a suspensão foi incubada por 1 hora e, posteriormente, centrifugada a $15000 \mathrm{x}$ g, por 15 minutos. Todo o procedimento foi realizado a $4^{\circ}$ C, sendo que o sobrenadante obtido constituiu o extrato enzimático. No sobrenadante foi determinado o teor de proteínas pelo método descrito por LOWRY et al. (1951), adaptado por Toralles (2005).

\subsubsection{Atividade da Poligalacturonase (PG) - (E.C. 3.2.1.15)}


A atividade de poligalacturonase (PG) foi determinada conforme o método descrito por PRESSEY (1986) adaptado de PRESSEY e AVANTS (1973), através de reação entre o extrato enzimático com solução de ácido poligalacturônico a 0,25\% em tampão acetato de sódio 37,5 mM, $\mathrm{pH} 5,0$, a $30^{\circ} \mathrm{C}$, por 3 horas. A reação foi interrompida em banho-maria $\left(100^{\circ} \mathrm{C}\right)$ e os grupos redutores liberados foram determinados segundo a técnica de SOMOGYI adaptada por NELSON (1944), usando-se glicose anidra como padrão. A unidade de atividade enzimática (UAE) é definida como a capacidade de a enzima catalisar a formação de um nanomol de açúcar redutor por minuto de reação por grama de amostra, nas condições de ensaio.

\subsubsection{Atividade da Pectinametilesterase (PME) - (E.C.3.1.1.11)}

A determinação da atividade das PME utilizou adaptações das técnicas descritas por JEN e ROBINSON (1984) e por PAYNTER e JEN (1974). O extrato bruto foi incubado com solução de pectina cítrica (1\% em NaCl 0,2 N- pH 7,0), acompanhando-se a desmetilação da pectina por 10 minutos, com o pH do meio reacional constante em 7,0 , a $30^{\circ} \mathrm{C}$, por meio de titulação com solução de $\mathrm{NaOH}$ 0,01N. Uma unidade de atividade enzimática foi definida como a quantidade de enzima capaz de catalisar a desmetilação de pectina correspondente ao consumo de $1 \mathrm{nmol}$ de $\mathrm{NaOH}$ por grama de matéria fresca.

\subsubsection{Determinação do pH e temperatura ótimos.}

O efeito do pH na atividade da PME e PG foi determinado a $30^{\circ} \mathrm{C}$, na faixa de $\mathrm{pH}$ entre $3,0 \mathrm{e}$ 9,0 usando tampões apropriados (100mM citrato-200mM fosfato e $100 \mathrm{mM}$ Tris- $\mathrm{HCl})$. O pH ótimo determinado no ensaio foi utilizado em todos outros experimentos. Já, para o efeito da temperatura na PME e PG, a atividade foi determinada entre $15^{\circ} \mathrm{C}$ e $80^{\circ} \mathrm{C}$ usando banho circulante (Marconi, Piracicaba/SP, Brasil). Os meios reativos com e sem extrato enzimático foram separadamente termostatizados por 5 minutos, nas temperaturas indicadas e, posteriormente, avaliados.

\subsubsection{Estabilidade térmica, parâmetros de Arrhenius e tempo de meia-vida.}

Alíquotas $(500 \mathrm{~L})$ de solução do extrato enzimático foram previamente aquecidas entre $30^{\circ}$ $\mathrm{C}$ e $70^{\circ} \mathrm{C}$ para $\mathrm{PG}$ e, entre $30^{\circ} \mathrm{C}$ e $100^{\circ} \mathrm{C}$ para PME, em tubos de ensaio com tampas (i.d $9 \mathrm{~mm}$, parede $1 \mathrm{~mm}$ ) por períodos de tempo variando entre 0 e 540 segundos. Posteriormente, as amostras foram rapidamente resfriadas e a atividade restante foi determinada usando o mesmo procedimento descrito anteriormente (ROS et al., 1992; 1993). As constantes de velocidade de desnaturação de 
primeira-ordem $(\mathrm{k})$ foram determinadas a partir das inclinações das curvas de desnaturação, de acordo com equação 1, a seguir (DRAETTA et al., 1979; ANTHON, 2002; TORALLES, 2005):

$$
\log \left(\frac{A_{t}}{A_{o}}\right)=-(k / 2.303) t \quad \text { ou } \ln \left(\frac{A_{t}}{A_{o}}\right)=-k t \quad-(E q .1)
$$

Onde, $A_{o}$ é a atividade inicial da enzima e $A_{t}$ é a atividade após o tempo de aquecimento. As inclinações foram determinadas por regressão linear e as constantes de inativação foram representadas graficamente segundo Arrhenius. As energias de ativação (Ea) foram calculadas a partir da inclinação do gráfico de Arrhenius, $\ln (\mathrm{k})$ contra 1/T, de acordo com equação 2, abaixo,

$$
\ln (k)=-E a / R T+\ln A \quad-(E q .2)
$$

Onde, $\mathrm{R}$ é a constante universal dos gases $\left(8.314 \mathrm{~J} \cdot \mathrm{mol}^{-1} \cdot \mathrm{K}^{-1}\right)$, T é a temperatura em $\mathrm{K}$ e A é a constante ou fator pré-exponecial. As inclinações foram calculadas por regressão linear.

Meia-vida $\left(\mathrm{t}_{1 / 2}\right)$ de uma substância é o tempo para sua concentração cair pela metade do valor inicial. O tempo para $A$ diminuir de $A_{o}$ até $1 / 2 A_{0}$, em uma reação de primeiro-ordem, é determinado através da equação 3, abaixo,

$$
k \cdot t_{\frac{1}{2}}=-\ln \left(\frac{\frac{1}{2} A_{o}}{A_{o}}\right)=-\ln (1 / 2)=\ln 2_{\text {ou seja }} t_{\frac{1}{2}}=\frac{\ln 2}{k} \quad-(E q .3)
$$

Para uma reação de primeira-ordem, o tempo de meia-vida é independente da concentração inicial.

\subsubsection{Efeitos da concentração do substrato pectina e da concentração salina sobre a atividade da PME.}

As amostras foram tratadas conforme a metodologia anteriormente descrita, variando a concentração do $\mathrm{NaCl}$ e da pectina utilizados para a incubação do extrato enzimático. As concentrações salinas utilizadas foram 0,1 Molar (M), 0,2 M, 0,5 M, 1,0 M e 2,0 M enquanto a concentração da pectina foi de 0,5\%,1,0\% e 1,5\%. Compararam-se os efeitos da concentração salina e do substrato pectina sobre a atividade enzimática.

\subsubsection{Análise estatística}

Os dados obtidos nos testes foram avaliados pela ANOVA fazendo uso do pacote computacional Statistic for Windows 5.1. Os coeficientes de cada parâmetro linear foram determinados pelo método dos mínimos quadrados usando as funções estatísticas do Software 
Statgraphs plus for Windows. Já o Método de regressão não-linear foi aplicado através do pacote computacional Statistic for Windows 5.1.

\section{RESULTADOS E DISCUSSÃO}

\subsection{Atividade enzimática da PG e PME e características químicas de oito cultivares de pêssegos}

Os resultados das análises físicas e químicas para os frutos das diferentes cultivares de pêssegos podem ser observadas na Tabela 1.1, a seguir.

Tabela 1.1. Características químicas dos frutos das diferentes cultivares de pêssegos.

\begin{tabular}{llcl}
\hline \multicolumn{1}{c}{ TRATAMENTO / CULTIVAR } & \multicolumn{1}{c}{$\begin{array}{c}\text { SST } \\
\left.\text { ( }{ }^{\text {Brix }}\right)\end{array}$} & $\begin{array}{c}\text { AT } \\
\text { (\% Ac. Cítrico) }\end{array}$ & \\
\hline Granada & $10,83 \mathrm{a}^{*}$ & $0,80 \mathrm{c}$ & $13,60 \mathrm{a}$ \\
Jade & $13,60 \mathrm{~d}$ & $0,76 \mathrm{~b}$ & $17,82 \mathrm{c}$ \\
Esmeralda & $11,30 \mathrm{~b}$ & $0,77 \mathrm{~b} \mathrm{c}$ & $14,68 \mathrm{~b}$ \\
Diamante & $13,73 \mathrm{~d}$ & $0,75 \mathrm{~b}$ & $18,23 \mathrm{c}$ \\
Granito & $11,63 \mathrm{~b}$ & $0,86 \mathrm{~d}$ & $13,58 \mathrm{a}$ \\
Maciel & $12,60 \mathrm{~b} \mathrm{c}$ & $0,88 \mathrm{~d}$ & $14,33 \mathrm{a} \mathrm{b}$ \\
Eldorado & $13,40 \mathrm{c} \mathrm{d}$ & $0,55 \mathrm{a}$ & $24,52 \mathrm{~d}$ \\
Jubileu & $13,40 \mathrm{c} \mathrm{d}$ & $0,56 \mathrm{a}$ & $23,80 \mathrm{~d}$ \\
\hline
\end{tabular}

- Letras distintas na coluna indicam diferenças significativas pelo teste de Tukey em nível de 5\% de significância.

Os valores de $\mathrm{pH}$ não diferiram significativamente entre as diferentes cultivares, apresentando um valor médio de 3,60 $\pm 0,18$. Sendo que os valores observados para o pH estão de acordo com aqueles descritos na literatura para as cultivares estudadas (MEDEIROS e RASEIRA, 1998; VERSARI et al., 2002).

O SST, de um modo geral, acompanhou o ciclo de colheita, conforme o descrito por MEDEIROS e RASEIRA (1998), com exceção da cultivar precoce Jade que foi significativamente superior às demais, fato já descrito por TORALLES (2005). Os maiores valores de SST foram apresentados pelas cultivares Jade, Diamante, Eldorado e Jubileu que não diferiram significativamente entre si.

A acidez das cultivares tardias Jubileu $(0,56 \%)$ e Eldorado (0,55\%) foi significativamente inferior. A acidez cresce para as cultivares Diamante, Esmeralda e Jade, que não diferiram entre si. 
Os valores de acidez foram superiores aqueles determinados por VERSARI (2002) para as cultivares Redhaven, Suncrest e Maria Marta, mas aproximam-se dos descritos por MEDEIROS e RASEIRA (1998) para as cultivares em estudo.

O SST/AT apresentou maior índice para as cultivares Eldorado $(24,52)$ e Jubileu $(23,80)$, seguido pelas cultivares Jade $(17,82)$ e Diamante $(18,23)$. Esta relação é importante, pois é um dos principais indicadores de frutas de alta qualidade, principalmente quando SST/AT 15,1. As demais cultivares foram significativamente inferiores. Ressalta-se que os resultados de SST/AT estão intimamente relacionados com a aceitabilidade dos sucos e outros derivados de frutas (WHINKLER, 1932; MEREDITH et al., 1989; TORALLES, 2005).

$\mathrm{Na}$ Figura 1.1 podemos observar a atividade enzimática relativa da PG e PME para cultivares de pêssegos em estudo.

Figura 1.1 - Atividades relativas da PG e PME, in vitro, para cultivares brasileiras de pêssegos: (a) atividade máxima da PG - 1,117 UAE (Cultivar Esmeralda), a $30^{\circ}$ C; (b) atividade máxima da PME - 6000 UAE (Cultivar Esmeralda), a 30 ${ }^{\mathrm{o}} \mathrm{C}$.

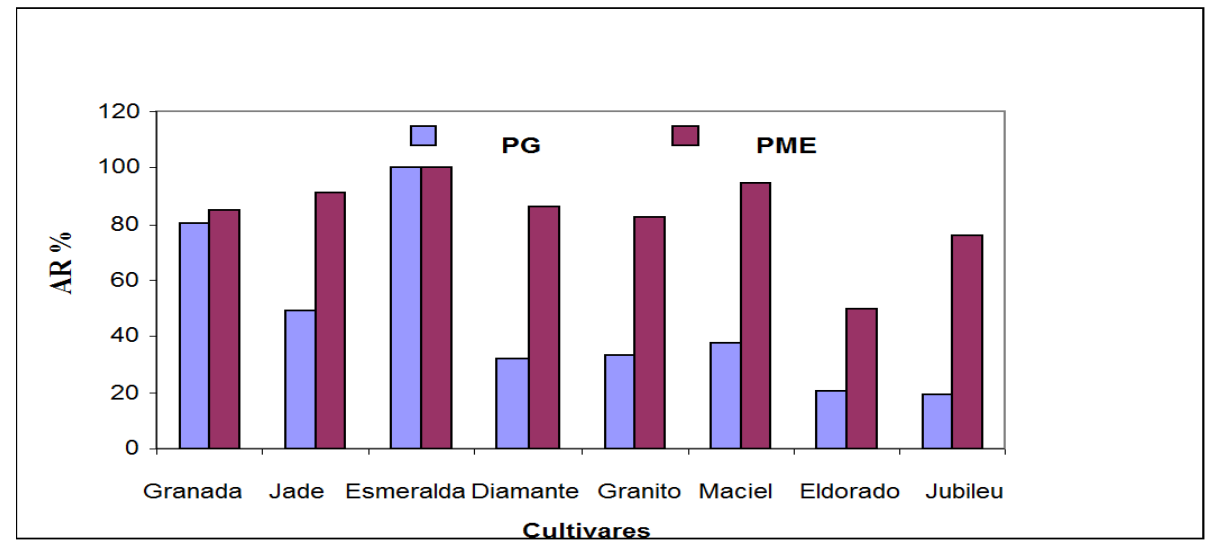

Os valores das atividades relativas tanto da PG como da PME variaram significativamente entre as cultivares. Para a PG as cultivares Jubileu e Eldorado apresentaram os menores valores, diferindo significativamente das demais. As cultivares Esmeralda e Granada apresentaram os maiores valores de atividade diferindo das demais e entre si, apresentando, a cultivar Esmeralda a maior atividade enzimática. Para a PME, observou-se que a cultivar Eldorado apresentou os menores valores de atividade enzimática seguida das cultivares Jubileu e Granito diferindo significativamente dos demais. As cultivares Jade e Maciel apresentaram os maiores valores de atividade de PME, diferindo significativamente das demais.

A cultivar Eldorado apresentou os menores valores de atividade in vitro, tanto para PG quanto para PME, por isso foi utilizada para a continuação dos estudos das propriedades e estabilidade destas enzimas em pêssegos brasileiros. 


\subsection{Características físicas e químicas de pêssegos da cultivar Eldorado}

As características físicas e químicas dos pêssegos da cultivar Eldorado podem ser observadas na Tabela 1.2.

Tabela 1.2 - Características físicas e químicas de pêssegos da cultivar Eldorado (Safra 2004/2005).

\begin{tabular}{lc}
\hline \multicolumn{1}{c}{ PARÂMETROS } & VALORES * \\
\hline $\mathrm{pH}$ & $3,7 \pm 0,1$ \\
Sólidos Solúveis Totais ( ${ }^{\text {B Brix })}$ & $13,4 \pm 0,1$ \\
Acidez Titulável Total (\% Ácido Cítrico) & $0,55 \pm 0,01$ \\
Relação SST/AT & $24,52 \pm 0,55$ \\
Teor de Ácido Ascórbico (mg/100 ml) & $0,18 \pm 0,01$ \\
Teor de Fenóis (ppm) & $305,87 \pm 5,64$ \\
\hline
\end{tabular}

- Média \pm desvio padrão.

O teor de sólidos solúveis e o teor de fenóis são relativamente elevados enquanto a acidez titulável total é um pouco mais baixa o que pode ser atribuído ao fato de se tratar de uma cultivar semi-tardia. Um alto valor foi encontrado para a relação SST/AT da cv. Eldorado $(24,52)$, que é considerado um parâmetro indicador de maturidade e de frutas de alta qualidade (WINKLER, 1932). TORALLES (2005), para a safra 2003/2004, determinou que a relação SST/AT é de 22,27 para esta cultivar e, observou que este parâmetro foi um indicador superior de qualidade sensorial para elaboração de purês de pêssegos (TORALLES, 2005).

\section{$3.3 \mathrm{pH}$ e temperatura ótimos}

O pH ótimo para a PG e PME pode ser observado nas Figuras 1.2 e 1.3, a seguir, relacionando a atividade enzimática relativa com o pH de determinação.

Figura 1.2 - Efeitos do pH na atividade da PME de pêssegos da cultivar Eldorado, temperatura de $30^{\circ} \mathrm{C} \pm 0,2^{\circ} \mathrm{C}$ (os pontos indicam as médias obtidas).

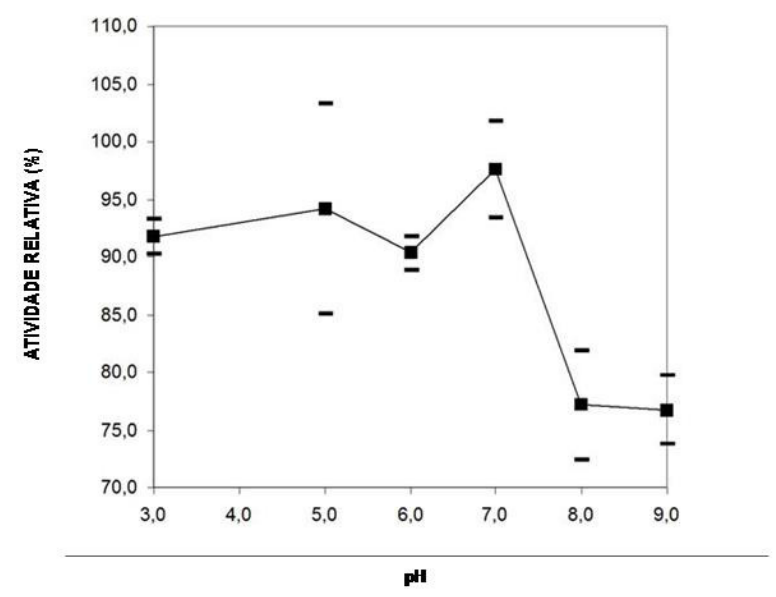


Figura 1. 3 - Efeitos do pH na atividade da PG de pêssegos da cultivar Eldorado,temperatura de $30^{\circ} \mathrm{C} \pm 0,2^{\circ} \mathrm{C}$ (os pontos indicam as médias obtidas).

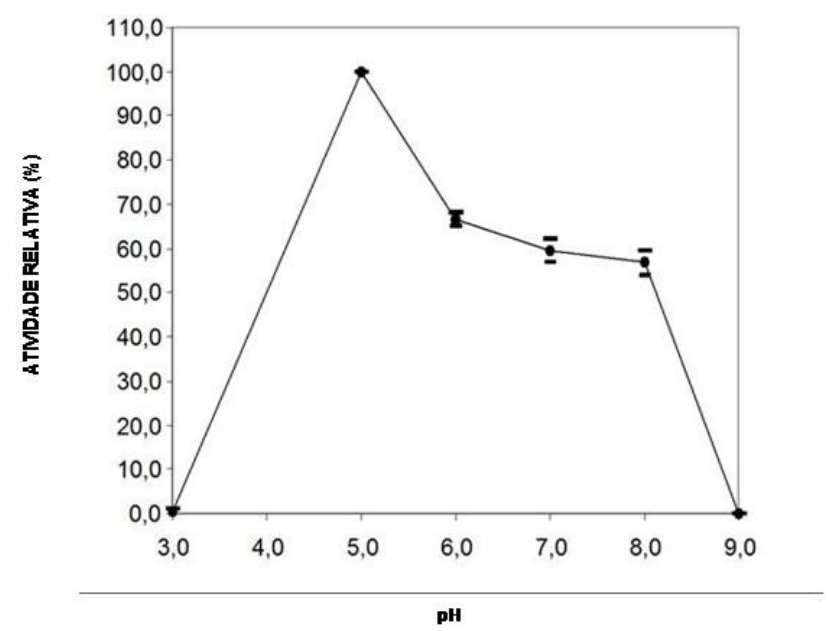

A PG mostrou máxima atividade no entorno do $\mathrm{pH}$ 5,0 enquanto na atividade da PME foram observados dois pontos (picos) de atividade nos $\mathrm{pH}$ 5,0 e 7,0, sendo que a máxima atividade foi observada no $\mathrm{pH} 7,0$.

A presença de dois picos, conforme WHITAKER (1994) pode indicar a ocorrência de duas isoenzimas da PME em pêssegos. A ocorrência de isoenzimas de PME, em tomates, também é reportada por CRELIER et al. citados por ANTHON et al. (2002), que indicaram que estas isoenzimas têm suas atividades máximas em pH 5,0 e 7,5. PRESSEY e AVANTS (1973) determinaram como pH ótimo para PG I 5,5 e, para PG II 4,0, sendo que para a atividade conjunta das duas enzimas observaram-se condições ótimas em pH 5,5.

Embora vários estudos indiquem a ocorrência de 3 isoenzimas da $\mathrm{PG}$, não foram observadas, no gráfico da Figura 1.3, a presença de isoenzimas para PG (PRESSEY e AVANTS, 1973; WHITAKER, 1994; ROS et al., 1992, 1993; ANTHON et al., 2002).

No $\mathrm{pH} 3,7$, característico dos frutos da cultivar Eldorado, observou-se um predomínio da atividade da PME em relação à atividade da $\mathrm{PG}$. Nesse pH, a $\mathrm{PG}$ reteve $46,42 \%$ de sua atividade enquanto a PME reteve $89,50 \%$ de sua atividade relativa. Os resultados indicam a importância da dependência do $\mathrm{pH}$, de ambas enzimas, para a degradação de substâncias pécticas, seu controle e aplicações tecnológicas, estando de acordo com o descrito por ROS et al., (1993 a, b).

A influência da temperatura sobre a atividade da PG e PME é demonstrada na Figura 1.4. 
Figura 1.4 - Efeitos da temperatura na atividade da PG e PME de pêssegos do cultivar Eldorado, pH 5,0 \pm 0,1 para PG e $\mathrm{pH} 7,0 \pm 0,1$ para PME (os pontos indicam as médias obtidas).

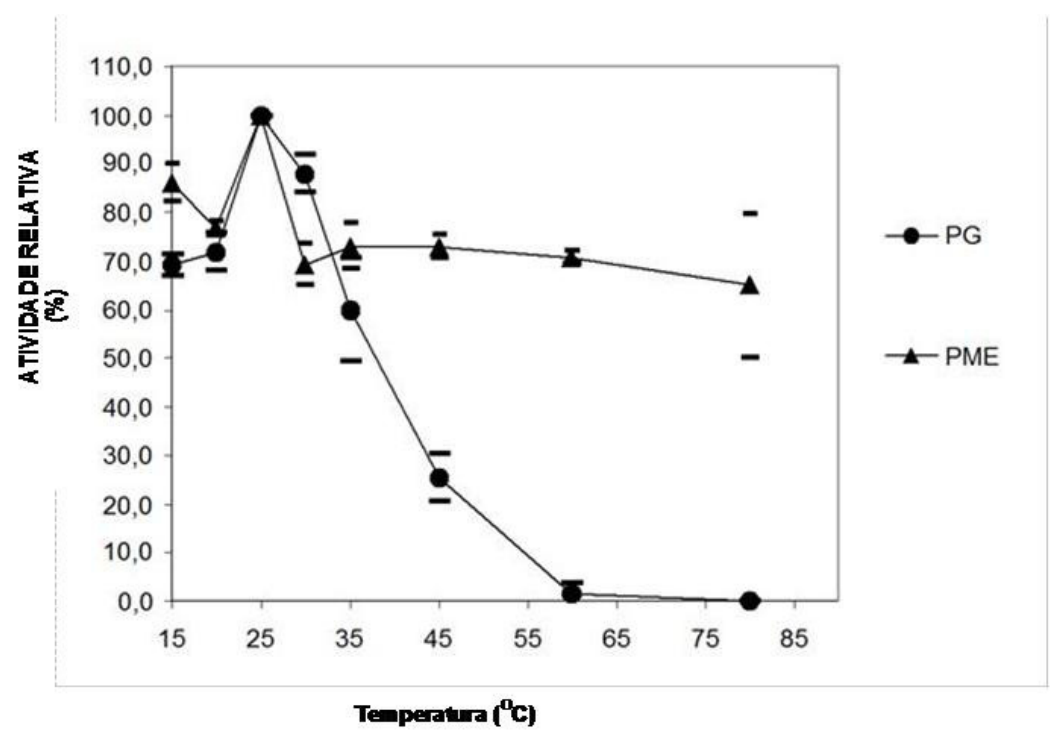

Para ambas as enzimas a temperatura ótima foi a de $25^{\circ} \mathrm{C}$. A estabilidade da PG foi significativamente menor que a da PME a partir da temperatura de $45^{\circ} \mathrm{C}$. Observou-se que a atividade relativa da $\mathrm{PG}$ decresce de $88,0 \%$ na temperatura de $30^{\circ} \mathrm{C}$ para $1,4 \%$ na temperatura de $60^{\circ} \mathrm{C}$, não apresentando atividade em temperaturas acima de $80^{\circ} \mathrm{C}$. Estes resultados estão de acordo com o descrito por ROS et al. (1993 a, b), que observou um acentuado decréscimo na atividade relativa das $\mathrm{PG}$ a partir de $50^{\circ} \mathrm{C}$, apresentando uma atividade residual muito próxima de zero a $80^{\circ} \mathrm{C}$. Para ROS et al. (1993) a temperatura ótima para as duas isoenzimas de PG em Rhizopus nigricans, é de $50^{\circ} \mathrm{C}$. A observação de temperatura ótima de $25^{\circ} \mathrm{C}$ deve-se, provavelmente, à presença ou ao predomínio de apenas uma isoenzima, a Exopoligalacturonase, nos frutos de pêssegos cv. Eldorado, pois esta isoenzima apresenta ótimo de temperatura mais baixo que a sua variante endopoligalacturonase (ROSS et al.,1993 a, b).

Já a PME se manteve estável, mesmo sob temperaturas mais altas, pois se observou que conservou 69,40\% de sua atividade relativa em uma temperatura de $80^{\circ} \mathrm{C}$ (ANTHON et al., 2002; TORALLES, 2005).

Em PPO e POD de pêssegos da cv. Granada, TORALLES et al. (2004 a) observaram comportamento semelhante quanto a estabilidade, ou seja, a POD teve um decréscimo acentuado da estabilidade a partir dos $40^{\circ} \mathrm{C}$ quando comparado com a PPO. LIMA (2002 a) considera que as mudanças na atividade da PME são comuns, sendo influenciadas pela temperatura, pH, por isoformas da enzima ou por inibidores enzimáticos, muitas vezes gerados pela própria enzima, 
como o $\mathrm{H}_{3} \mathrm{O}^{+}$gerado pela enzima ao desmetilar seus substratos. PAYNTER e JEN (1974) indicam $30^{\circ} \mathrm{C}$ como temperatura ótima de ação da PME em pêssegos das cultivares Rehaven e Redskin.

\subsection{Parâmetros de Arrhenius, energias de ativação e tempos de meia vida.}

Pode-se observar na Figura 1.5, a seguir, as curvas de inativação térmica para a poligalatorunase, em frutos de pêssegos da cultivar Eldorado.

Figura 1.5 - Termoinativação da Poligalatorunase de pêssegos da cultivar Eldorado. Tempos de aquecimento indicados para: $30^{\circ} \mathrm{C}() ; 60^{\circ} \mathrm{C}(\boldsymbol{\square}) ; 80^{\circ} . \mathrm{C}(\boldsymbol{\Delta}) ; 100^{\circ} \mathrm{C}()$. Obs.: Os pontos dos símbolos abertos não foram usados para regressão linear.

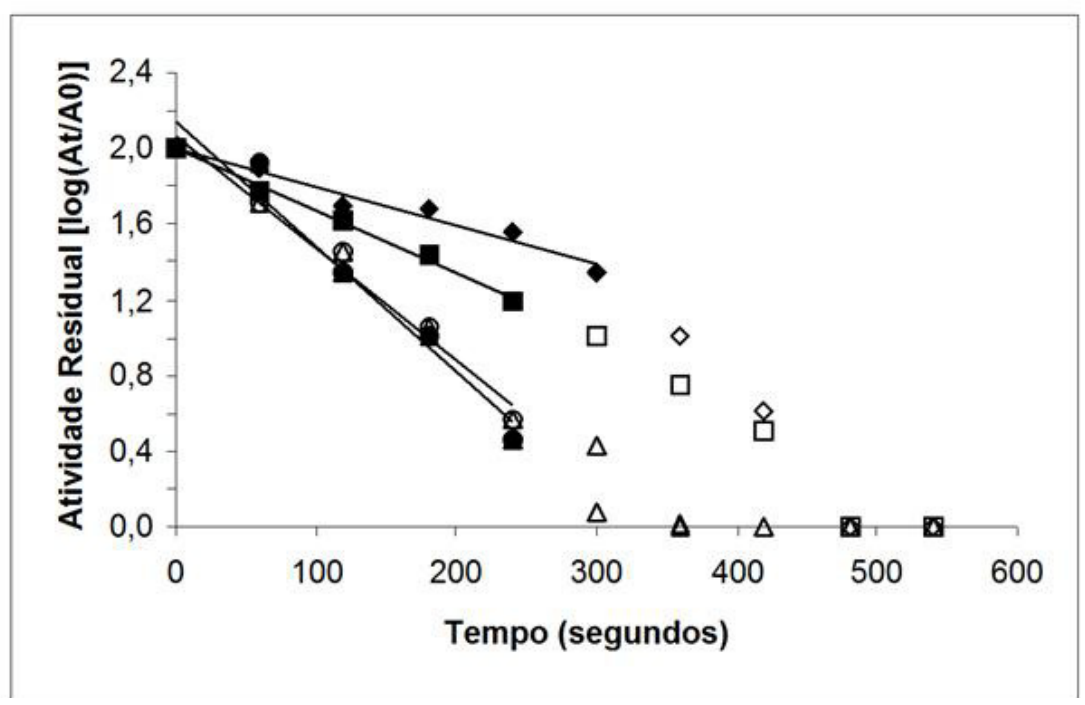

As retas observadas na regressão linear mostrada na Figura 1.5 correspondem às equações I, II, III e IV, abaixo:

$$
\begin{gathered}
\mathrm{Y}\left(30^{\circ} \mathrm{C}\right)=-0,0021 \mathrm{x}+2,001, \mathrm{R}^{2}=0,9649(E q . I) \\
\mathrm{Y}\left(50^{\circ} \mathrm{C}\right)=-0,0033 \mathrm{x}+1,9966, \mathrm{R}^{2}=0,9947(E q . I I) \\
\mathrm{y}\left(60^{\circ} \mathrm{C}\right)=-0,0059 \mathrm{x}+2,0632, \mathrm{R}^{2}=0,9818(E q . I I I) \\
\mathrm{y}\left(70^{\circ} \mathrm{C}\right)=-0,0067 \mathrm{x}+2,1471, \mathrm{R}^{2}=0,9612(E q . I V)
\end{gathered}
$$

A inativação térmica da poligalacturonase seguiu, aparentemente, um ajuste linear, típico de uma cinética de primeira ordem. Observa-se que sua atividade residual, Log $\left(\mathrm{A}_{t} / \mathrm{A}_{0}\right)$, foi tipicamente linear para temperaturas compreendidas entre 30 e $70^{\circ} \mathrm{C}$, em tempos de aquecimento de até 300 segundos. Os desvios de linearidade observados em tempos de aquecimento acima de 360 segundos, reforçam a hipótese abordada anteriormente, de haver a presença ou predominância de uma segunda isoenzima mais resistente, provavelmente a exopoligalacturonase (ROS et al., 1993 a, b). 
As curvas de termoinativação da Pectinametilesterase (PME) podem ser observadas na Figura 1.6.

Figura 1.6 - Termoinativação da Pectinametilesterase de pêssegos da cultivar Eldorado. Tempos de aquecimento indicados para: $30^{\circ} \mathrm{C}() ; 60^{\circ} \mathrm{C}(\boldsymbol{\Delta}) ; 80^{\circ} . \mathrm{C}(\boldsymbol{\square}) ; 100^{\circ} \mathrm{C}(*)$.Obs.: Os pontos dos símbolos abertos não foram usados para regressão linear.

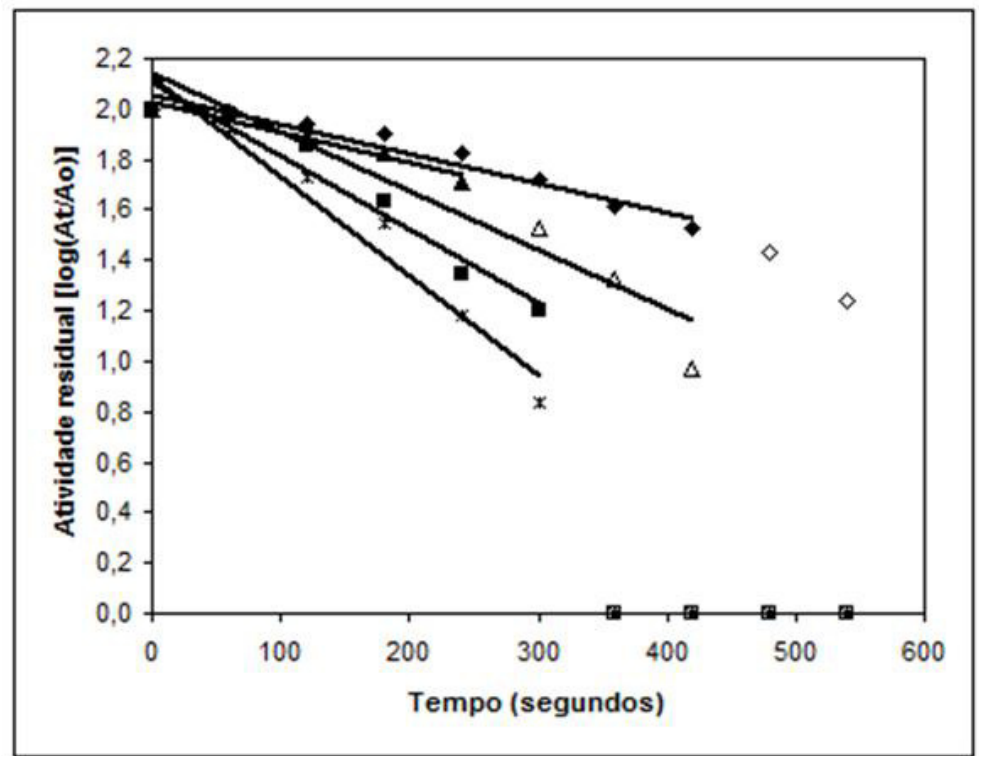

As retas observadas na regressão linear mostrada na Figura 1.6 correspondem às equações V, VI, VII e VIII, abaixo:

$$
\begin{gathered}
\mathrm{Y}\left(30^{\circ} \mathrm{C}\right)=-0,0012 \mathrm{x}+2,0599, \mathrm{R}^{2}=0,9509(E q . V) \\
\mathrm{Y}\left(60^{\circ} \mathrm{C}\right)=-0,0023 \mathrm{x}+2,1424, \mathrm{R}^{2}=0,8972(E q . V I) \\
\text { y }\left(80^{\circ} \mathrm{C}\right)=-0,0029 \mathrm{x}+2,1056, \mathrm{R}^{2}=0,9459(E q . V I I) \\
\text { y }\left(100^{\circ} \mathrm{C}\right)=-0,0039 \mathrm{x}+2,1222, \mathrm{R}^{2}=0,95(E q . V I I I)
\end{gathered}
$$

Observa-se uma queda mais rápida da atividade em temperaturas acima de $80^{\circ} \mathrm{C}$, desaparecendo sua atividade em tempos acima de 480 segundos. Já em temperaturas menores, como de $60^{\circ} \mathrm{C}$, em 480 segundos a enzima perdeu cerca de $50 \%$ de sua atividade relativa inicial. A termoinativação da PME obedeceu a um aparente ajuste linear ou cinético de primeira ordem, para todas as temperaturas de ensaio, em tempos de aquecimento de até 420 segundos.

A variação de comportamento entre as temperaturas sugere a presença de uma segunda isoenzima de PME, com maior resistência térmica, como demonstrado por ANTHON et al. (2002), para PME em sucos de tomates. Pois a queda de atividade acentuada acima de temperaturas de $80^{\circ} \mathrm{C}$ sugere uma modificação catalítica das isoenzimas, influenciada pelas ligações não covalentes típicas das estruturas enzimáticas (ligações heterólogas). Estas ligações envolvem diversos tipos de interações intermoleculares fracas (Forças de Van der Walls, Pontes de hidrogênio, interações 
eletrostáticas e hidrofóbicas) WHITAKER (1994). As temperaturas mais altas desestruturam estas interações desnaturando a proteína.

Para PME, a influência da desestruturação da proteína sobre a atividade enzimática ocorre a partir de temperaturas de $80^{\circ} \mathrm{C}$ enquanto para a $\mathrm{PG}$ o fenômeno ocorre a partir de $60^{\circ} \mathrm{C}$, indicando ser esta enzima menos termoestável que a PME.

A partir dos dados de termoinativação da PG e PME construiu-se o Gráfico de Arrhenius, considerando uma regressão linear, com variância em torno da média acima de 95\%. O Teste $\mathrm{F}$ indica que o modelo de Arrhenius é estatisticamente significativo ao nível de $95 \%$ para PG e ao nível de 97,50\% para a PME. O Gráfico de Arrhenius para termoinativação da PG e PME pode ser observado na Figura 1.7.

Figura 1.7 - Gráfico de Arrhenius da constante de velocidade de termoinativação para PG(ロ) e PME( $\mathbf{\Delta})$, em pêssegos da cultivar Eldorado. Obs.: Os pontos dos símbolos abertos não foram usados para regressão linear.

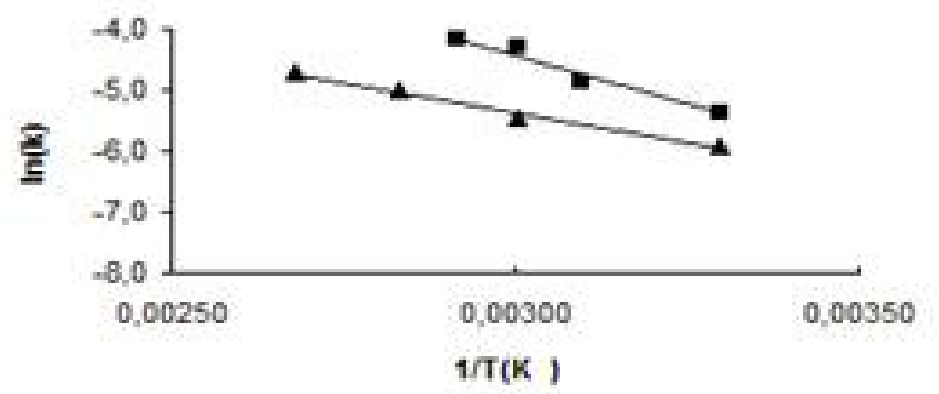

Das inclinações das retas da Figura 1.7 acima:

$$
\begin{aligned}
& \text { “y }=-3232,3 x+5,2722 ”(P G) e, \\
& “ y=-1977,4 x+0,5718 ”(P M E),
\end{aligned}
$$

foram calculadas as energias de ativação (Ea) para PG e PME, onde

$$
\mathrm{I}_{\text {reta }}=-\mathrm{Ea} / \mathrm{R}
$$

As Energias de ativação da PG e PME são respectivamente 26,87 kJ. Mol ${ }^{-1}$ e 16,44 kJ. Mol ${ }^{-1}$. Pode-se observar, na tabela 1.3, os parâmetros de inativação da PG e PME em pêssegos da cultivar Eldorado. 
Tabela 1.3 - Parâmetros de inativação da PG e PME em pêssegos da cultivar Eldorado.

\begin{tabular}{cccccccc}
\hline Enzima & \multicolumn{7}{c}{ Parâmetros } \\
\hline & $\mathrm{T}_{\text {ref }}$ & $\mathrm{K}_{\text {ref }} \times 10^{3 \mathrm{a}}$ & $\mathrm{K}_{\text {obs }} \times 10^{3 \mathrm{~b}}$ & $\mathrm{~T} \mathrm{1/2}$ & $\mathrm{Ea}^{\mathrm{c}}$ & $\mathrm{LnA}^{\mathrm{c}}$ & $\mathrm{R}^{2}$ \\
& $\left({ }^{\circ} \mathrm{C}\right)$ & $\left(\mathrm{s}^{-1}\right)$ & $\left(\mathrm{s}^{-1}\right)$ & $(\mathrm{s})$ & $\left(\mathrm{kJ} . \mathrm{mol}^{-1}\right)$ & & \\
PG & 60 & 21 & 14 & 50,99 & $26,87 \pm 4,33 *$ & $5,27 \pm 1,60 *$ & 0,9507 \\
$\mathrm{PME}$ & 80 & 7,0 & 7,0 & 103,24 & $16,44 \pm 1,31 * *$ & $0,572 \pm 0,46 * *$ & 0,9875 \\
\hline
\end{tabular}

(a) Valor estimado para constante de velocidade de inativação na temperatura de referência.

(b) Valor observado para constante de velocidade de inativação na temperatura de referência.

(c) Valor \pm desvio padrão.

(*) Significância: p 0,05.

(**) Significância: p 0,0025.

A energia de ativação da PME foi menor que a da PG, fato também observado durante o ensaio de termoinativação, onde a PG teve uma queda substancial de sua atividade a partir da temperatura de $60^{\circ} \mathrm{C}$, enquanto que para a PME esta queda registrou-se a partir de $80^{\circ} \mathrm{C}$. Como se tratam de enzimas do mesmo grupo pode-se inferir que a PME é mais termoestável que a PG. Uma energia de ativação mais alta indica que uma menor variação de temperatura ou de tempos de exposição são necessários para inativar a enzima (TORALLES, 2005; WHITAKER, 1994).

Em contraste com a energia de ativação da PPO e POD de pêssegos da cv. Granada, os resultados de TORALLES (2005) foram bem maiores. Eles revelaram que a PPO $(\mathrm{Ea}=127,3 \mathrm{~kJ}$. $\mathrm{Mol}^{-1}$ ) foi mais termoestável do que a POD $\left(147,9 \mathrm{~kJ} . \mathrm{Mol}^{-1}\right)$. A $60^{\circ} \mathrm{C}$, temperatura de referência, os mesmos autores determinaram uma constante de velocidade de inativação igual a $3,4 \times 10^{-3} \mathrm{~s}$ para PPO, com meia-vida igual a 214,6 s.

Uma comparação entre os parâmetros de inativação observados para PG e PME, em pêssegos brasileiros, com os mesmos parâmetros descritos por TORALLES (2005) para PPO e POD, indica a PME como a enzima mais termoestável. Por outro lado, não existem, na literatura revisada, parâmetros determinados de constante de velocidade de inativação e energia de ativação para as enzimas PG e PME em pêssegos, não permitindo comparações diretas. O tempo de meiavida da PME foi maior que o da PG nas temperaturas de referência, comportamento observado em outras temperaturas. Para os pêssegos cv. Eldorado os resultados indicaram que a PME tem uma termoestabilidade maior que a PG, podendo, portanto, ser utilizada como indicador de termoinativação para controle durante o processamento tecnológico de sucos e polpas de pêssegos. 


\subsection{Efeitos da concentração salina e da concentração do substrato pectina sobre a atividade da}

PME.

O Efeito da concentração salina e da concentração de pectina, utilizadas na incubação do extrato enzimático, sobre a atividade da PME de pêssegos cv. Eldorado pode ser observado na Figura 1.8.

Figura 1.8 - Efeito da concentração salina e da pectina sobre a atividade enzimática da PME, durante a incubação do extrato enzimático.

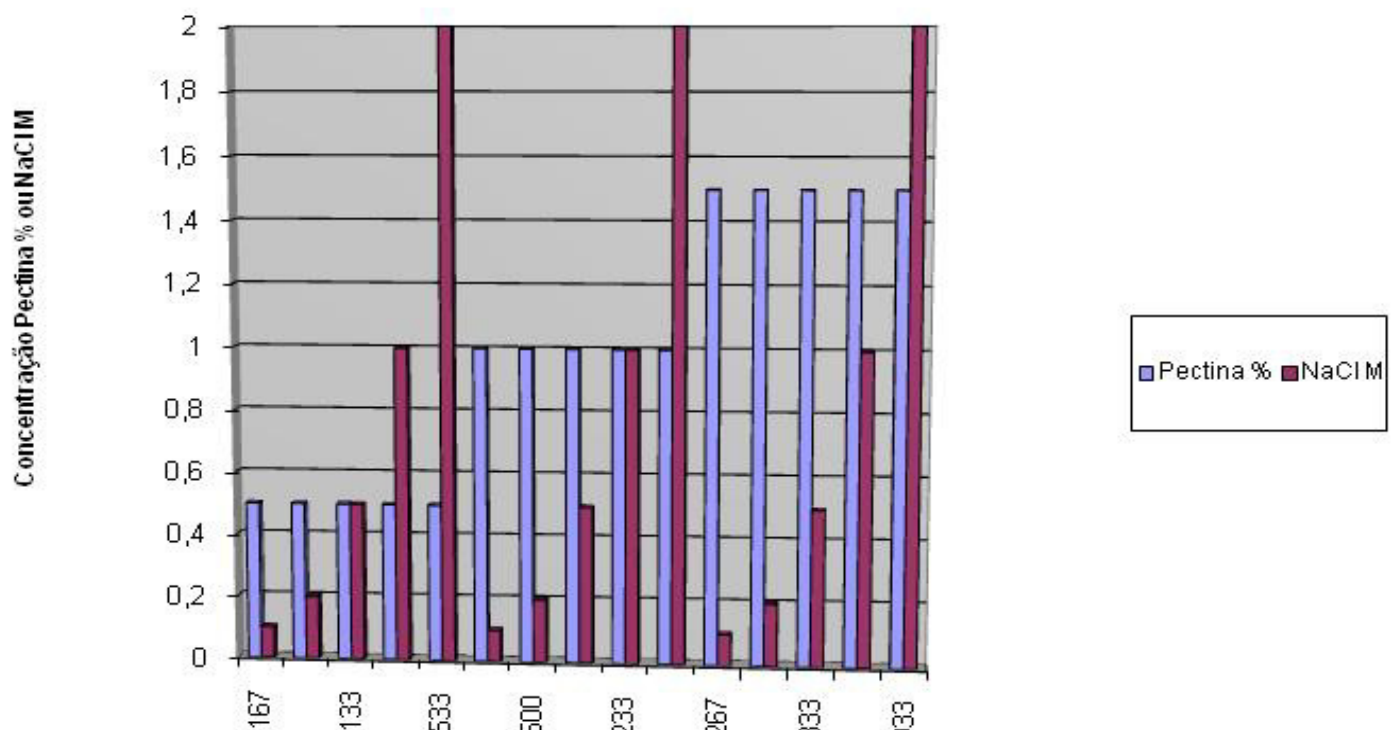

Observa-se que os valores da atividade enzimática crescem significativamente à medida que aumenta a concentração salina e, em menor grau, com o aumento da concentração do substrato pectina. Nos mesmos níveis de concentração salina não há variação significativa da atividade enzimática em função do aumento da concentração do substrato pectina.

A atividade enzimática da PME em pêssegos da cultivar Eldorado é influenciada, principalmente, pela concentração salina durante o período de incubação do extrato enzimático, atingindo seus maiores valores na concentração de 2,0 \% de $\mathrm{NaCl}$. Os resultados são corroborados por ROS et al. (1992) que indicaram que a concentração salina influi sobre a atividade da PME. Diversos estudos mostraram que a concentração de substrato e da concentração salina influem sobre a atividade da PME (ROS et al., 1992; WHITAKER, 1994; LIMA, 2002 a).

\section{CONCLUSÕES}

A cultivar Eldorado apresentou os menores valores de atividade relativa in vitro, para PG e PME, fator que determinou sua utilização para os estudos das propriedades e estabilidade destas enzimas em pêssegos brasileiros. 
A PG de pêssegos da cultivar Eldorado, apresentou máxima atividade no entorno do pH 5,0 e $25^{\circ} \mathrm{C}$ de temperatura. E, a PME, apresentou dois ótimos de $\mathrm{pH} 5,0$ e 7,0 com $25^{\circ} \mathrm{C}$ como temperatura ideal.

A concentração salina ideal para determinação de atividade da PME foi de $2 \%$ de $\mathrm{NaCl}$, com concentração de $1,5 \%$ do substrato pectina.

A inativação térmica da Poligalacturonase e da Pectinametilesterase seguiu um Modelo cinético de primeira ordem e a dependência com a Temperatura foi significativamente representada pela lei de Arrhenius.

A termodesnaturação foi efetiva para a $\mathrm{PG}$ em temperaturas acima de $60^{\circ} \mathrm{C}$, enquanto que, na PME, o efeito térmico só foi efetivo a partir dos $80^{\circ} \mathrm{C}$.

A termoestabilidade da PME foi maior do que a da PG podendo, a PME, ser utilizada como indicador de termoinativação para controle durante o processamento de pêssegos.

\begin{abstract}
This work objectived study the pectinolitics enzimatical properties in brazilian peaches. Pectic enzymes influence the fruits quality, especially climacterics fruits like peaches; therefore directly act on the fruits softening during its deterioration, reducing useful life. Also have importance on the processing of the fruits, therefore are directly related with the product viscosity, influencing operations as clarification and concentration. This work studied the PME (pectin methylesterase) and PG (polygalactorunase) properties of Granada, Esmeralda, Jade, Diamante, Granito, Maciel, Eldorado and Jubileu clingstone peaches, defining the stablest enzyme of $i$. The PG activity used PRESSEY (1986) methodology and the PME determination used JEN \& ROBINSON (1984) methodology. For the physical and chemical properties were used AOAC (2000) methodology. For Eldorado clingstone peaches PG enzymes the highest activity was in pH 5,0 and for PME was in $\mathrm{pH}$ 7,0. For both enzymes, $25^{\circ} \mathrm{C}$ was the best temperature. The PME stability was higher than PG. PME enzymes is the most stable enzyme from Eldorado clingstone peaches and can be used like thermoinativation indicator in the peach processing.
\end{abstract}

Key-words: Peaches; PME; PG; Thermical stability.

\title{
Referências
}

AOAC - Official Methods of Analysis of AOAC International. 17. ed. Maryland: AOAC International, 2000.

ANTHON, G.E.; SEKINE, Y.; WATANABE, N.; BARRET, D. Thermal inactivation of pectin methylesterease, polygalactorunase and peroxidaes in tomato juice. Journal of Agricultural and Food Chemistry. v. 50, p. 6153 $6159,2002$.

DRAETTA,I.S. Transformações enzímicas em nectarinas durante o armazenamento. Coletânea do ITAL. Campinas, v.10, p.33-43. 1979.

FACHINELLO, J.C.; NACHTIGAL, J.C.; KERSTEN, E. Fruticultura: fundamentos e práticas. Pelotas: Editora UFPEL, 1996. 311p.

FENNEMA, O R., Química de los alimentos. 2. ed. Zaragoza: ACRIBIA, 1993. 1095 p.

FOLHA DE SÃO PAULO. Mercado de sucos do Brasil em expansão. São Paulo, 23 de janeiro de 2000.

FREITAS, S. P.; SILVA, F. C.; LAGO, R. C. A.; COURI, S. Efeito de enzimas hidrolíticas no comportamento reológico do oleo de palma crú. Revista Ciência e Tecnologia de Alimentos. v.18. n.1. Campinas, 1998. 
GONÇALVES,N.B. Efeito da aplicação de cloreto de cálcio associado ao tratamento hidrotérmico sobre a composição química e suscetibilidade ao escurecimento interno do abacaxi cv.Smooth Cayenne. 1998. 101p.Tese (doutorado)- Universidade Federal de Lavras. Lavras.

GONZALEZ, A. R.; MAUROMOUSTAKOS, A.; PROKAKIS, G.; ASELAGE, J. Sugars and acidity of processing peaches in Arkansas. Arkansas Farm Research. v.41. n.1. p. 11-12. 1992.

GROSS, K.C. A rapid and sensitive spectrophotometric method for assaying polygalacturonase using 2-cyanoacetmide. Journal of Horticultural Science, v.17,n.6,p. 933-934. 1982.

JEN, J. J.; ROBINSON, M. L. Pectolytic enzymes in Sweet bell peppers (Capsicum annuum L.)Journal of Food Science. v49. n. 4. p. 1045-1087. Chicago, 1984.

JORNAL DO COMÉRCIO, Fruticultura no Brasil. Porto Alegre . 10 de setembro de 2001.

LIMA, H.C. Modificações de carboidratos estruturais e de enzimas pécticas em jabuticaba.. 61p.Tese (doutorado) - Universidade Federal de Lavras. Lavras, 2002. (A).

LIMA, M.A.C.. Alterações bioquímicas e fisiológicas durante a maturação e o armazenamento de graviola sob refrigeração associada a 1-metilciclopropeno e cera. 2002. 208 p. Tese(doutorado) - Universidade Federal do Ceará, Fortaleza. (B).

LOWRY, O. H.; ROSEBROUGH, N. J.; FARR, A. L.; RANDALLl, R. J. Protein measurement with the Folin phenol reagent. Journal Biological Chemistry, v. 193, p. 265-275, 1951.

LUH, B. S. Nectars, pulp juice and fruit juice blends. In: Fruit and vegetable juice processing technology. Nelson, $\mathrm{P}$ and Tressler, D. ed., Wesport: AVI, p. 436-505. 603 p.1980.

MEDEIROS, C e RASEIRA, M. (Org.) A cultura do pessegueiro. Brasilia: SPI, 1998.

MEREDITH. F. 1.; ROBERTSON, J. A.; HOVART. R. J. Changes in Physical and chemical parameters associated with quality and postharvest ripening of Harvester peaches. Journal Agricultural and Food Chemistry. v. 37, n. 5. p. 1210-1214, 1989.

NELSON, N. A photometric adaptation of the Somogyi method for the determination of glucose. Journal of Biology and Chemistry. v.153. p. 375. 1944.

PAYNTER, V. A.; JEN, J. J. Pectic enzymes in ripening peaches infected with Monilinia fructicola. Journal of Food Science. v.39. p. 1195-1199. Chicago, 1974.

PRESSEY, R. Extraction and assay of tomato polygalactorunases. Horticultural Science. v. 21. n.3. p. 490-492. 1986.

PRESSEY, R.; AVANTS, J. K. Separation and characterization of endopolygalactorunase and exopolygalactorunase from peaches. Plant Physiology. v. 52. p. 252-256. 1973.

PRESSEY, R.; AVANTS, J. K. Modes of action of carrot and peach exopolygalactorunase. Phytochemistry. v. 14 . n.4. p. 957-961. 1975.

ROBERTSON, J. A.. MEREDITH, F. 1., HOVART, R. J., SENTER, S. D. Effect of cold storage and maturity on the physical and chemical characteristic and volatile constituents of peach (Cv. Cresthaven ) Journal Agricultural and Food Chemistry, v. 38. p. 620-624. 1990.

ROS, J.M.; SAURA, D.; COLL, L.; LAENCINA, J. Métodos analíticos avanzados para la determinación de sustâncias pécticas y actividades enzimáticas pectolíticas. Alimentación equipos y tecnologia. p. 149-155. Madrid. 1992.

ROS, J.M.; SAURA, D.; COLL, L.; LAENCINA, J. On the response under different thermal treatments of the thermostable endoplygalacturonase produced by Rhizous nigricans. Z Lebensm Unters Forsch. V. 196. p. $356-359$. Berlim, 1993. 
SAINZ, R.L, SILVA, R.S., SILVA, E.B., VENDRUSCOLO, J.L., TORALLES, R.P \& ANTUNES, P.L. Atividade das poligalacturonases em frutos in natura e polpas congeladas de pêssegos (Prunus persica). Ciência e Tecnologia de Alimentos: Estratégia para o Desenvolvimento - Anais... Recife - PE: Sociedade Brasileira de Ciência e Tecnologia de alimentos - SBCTA, 2004. (a).

SAINZ, R.L, SILVA, R.S., SILVA, E.B., VENDRUSCOLO, J.L., TORALLES, R.P \& ANTUNES, P.L. Interferência de operações de conservação na atividade das poligalacturonases em polpas e pêssegos (Prunus persica) cv. eldorado. Ciência e Tecnologia de Alimentos: Estratégia para o Desenvolvimento - Anais... Recife - PE: Sociedade Brasileira de Ciência e Tecnologia de alimentos - SBCTA, 2004. (b).

SAINZ, R.L, SILVA, R.S., SILVA, E.B., VENDRUSCOLO, J.L., TORALLES, R.P \& ANTUNES, P.L. Determinação do ph ótimo de extração de pectinametilesterases em pêssegos (Prunus persica) cv.eldorado XIII Congresso de Iniciação Científica e VI Encontro de Pós-graduação - Anais... Pelotas: UFPel - 2004. (c).

SINGLETON, V.L.; ROSSI, J.A. Colorimetric of total phenolics with phosphomolybdic-phosphotungstic acid reagent. American Journal of Enology and Viticulture, v. 16, p. 144-158, 1965.

TORALlES, R. T.; VENDRUSCOLO. J. I_; HAAS. L. 1. R.; FERRI. N. L; DEL PINO, F. A. V.; ANTUNES, P. L. Caracterização parcial do escurecimento enzimático pela polifenoloxidase em pêssegos das cv. Granada, Jade, esmeralda e Maciel. Revista Brasileira de Agrociência, v. 10, n. 2, p. 241-244. Jan-mar. Pelotas, 2004 (a).

TORAlleS. R. P.; MALGARIM. M. B.; VENDRUSCUlO. J. L.; CANTILHANO, F. R. F.; TREPTOW, R. O. Parâmetros e atributos de qualidade para o processamento de purês de pêssegos brasileiros. Ciência e Tecnologia de Alimentos: Estratégia para o Desenvolvimento - Anais... Recife - PE: Sociedade Brasileira de Ciência e Tecnologia de alimentos - SBCTA, 2004. (b).

TORALLES, R.P. Purê de pêssego [Prunus persica(L.) Batsch]: escurecimento e controle, comportamento reológico e sensorial. 2005. 167 p. Tese (Doutorado em Ciência e Tecnologia Agroindustrial). Universidade Federal de Pelotas, Pelotas.

VERSARI, A.; CASTELLARI, M.; PARPINELLO, G.P.; RIPONI, C.; GALSSI, S. Characterization of peach juices obtained from cultivars Redhaven, Suncrest and Maria Marta grown in Italy. Journal of Food Chemistry. Londres: Elsevier, 76, p. 181-185. 2002.

VILAS BOAS, E.V. de B.; CHITARRA, A. B.; MALUF, W. R.; CHITARRA, M. I. F. Modificações texturais de tomates heterozigotos no loco alcobaça. Revista de Pesquisa Agropecuária Brasileira. Brasilia. v.35,n.7,p.1447-1453, 2000 .

WHITAKER, J. R. Principles of Enzimology for the food sciences. 2.ed. New York: Marcel Dekker, 1994, 625 p..

WINKLER, A. J. Maturity test table grapes. Californian Agricultural Experimention Stn. 1932. (Bulletin, 529).

WOODROOF, J. G. \& LUH, B. S. Commercial fruit processing. Wesport: The Avi Publishing Company, Inc., 1975.

YAMASAKI, M.T.; YASUI, T.; ARIMA, K. Pectic enzyme in the clarification of apple juice. Agricultural Biological Chemistry, 28: 779-87, 1964. 